\title{
HYDROLOGICAL CHARACTERISTICS THAT DETERMINE SUSPENDED SEDIMENT LOAD OF TROPICAL URBAN STORM EVENTS
}

\section{Daryl Lam}

Department of Geography, AS2, \#03-01, 1Arts Link, Kent Ridge, National University of Singapore, Singapore

117570

*geolrd@ nus.edu.sg (Corresponding author)

Received on $20^{\text {th }}$ May 2011, accepted in revised form $11^{\text {th }}$ July 2011

\begin{abstract}
Dwelling on the less investigated tropical urban river channels, this paper attempts to understand the hydrological characteristics that dominate and account for most of the suspended loads of individual events through intra-events SS concentrations-Discharge $(Q)$ relationship. Individual storm event has a variable signature due to the differing hydrological characteristics. As such, suspended sediment (SS) loads transported during storm events are never equivalent. A total of 34 storm events were determined from four gauging stations in the Kallang subcatchment, of the Marina Barrage Catchment, Singapore. There is a need for authorities to understand the nature of storm dynamics for optimal management of water resources in the new reservoir's catchment. Step-wise regression model was used to determine the dominating hydrological characteristics of the total loads during the storm events. Peak SS concentrations and the duration of high rainfall intensity $(>60 \mathrm{~mm} / \mathrm{h})$ are the main determinant of SS loads in the tropical urban waterways. Rapid rising and falling limbs of the storm hydrograph and short, intense storm events, typical of tropical, urban environment are explanations for the outcomes attained from the regression analysis.
\end{abstract}

(Keywords: Tropical urban catchment, Suspended Sediment, Discharge, Regression modeling, Hydrological Characteristics )

\section{INTRODUCTION}

There is much documentation of the significant impacts on water quantity and quality brought about by urbanization. However, as compared to research focusing on the issue of water quantity, urban water quality research is relatively marginalized (Goonetilleke and Thomas, 2003). The transport and fate of sediments in urban rivers are less researched on. Understanding sediment load is required in a wide spectrum of problems. These include erosion studies, reservoir sedimentation, design of dams, environmental impact assessment and problems of sediment-associated nutrients and pollution (Khanchoul \& Jansson, 2008).

Besides the 'urban' aspect, the humid, tropical region is 'data-poor' in terms of water quality studies (Bonell and Bruijnzeel, 2005). In Singapore, for example, with the exception of Chui's (1997) and Lim's $(2000,2003)$ works focusing on the country's urban catchments, there have been little efforts in understanding the intricate relationship between water quality and urbanization.
Tropical regions have very distinct climatic characteristics that may alter the dynamics of hydrological processes; the tropics are characterized by high magnitude and intensity of rainfall, and high temperatures. Intense thunderstorms bring about rapid input of water into a tropical urban catchment and such quantitative increase has direct impacts on the water quality. These include the first flush phenomenon and the dilution effect. These phenomenons have immense implications to the better understanding and management of water supply derived from the local catchments.

The goal of this study is to understand the dominating hydrological characteristics that control sediment loads during storm events in urban, tropical Singapore. Stepwise regression modeling will be used to sieve out the dominating hydrological characteristics from event-based data collected. A subsequent derivation of suspended sediment load through the hydrological characteristics can allow for mitigation works to be carried out by the relevant 
water agency and ensure the sustainability of the river-mouth reservoir through dredging of sediments in the reservoir or controlling sediments sources.

\section{AREA AND BACKGROUND OF STUDY}

Located at $1^{\circ} 22^{\prime} \mathrm{N}, 103^{\circ} 48^{\prime} \mathrm{E}$, Singapore has a uniform climate with a narrow annual temperature range of 25-31 ${ }^{\circ} \mathrm{C}$ and a high annual rainfall of 1650$2530 \mathrm{~mm}$. High temperature, humidity and rainfall are experienced throughout the year. The tropical monsoon brings about some seasonal variability within a year. December is characterized as the wettest month and the drier months are February and July. Two monsoon seasons can be identified from the rainfall patterns in Singapore - the Northeast monsoon (from late November to March) and the Southwest monsoon (from late May to early September). Storm events are usually short, with more than half of them lasting no more than an hour (Watt 1955, cited in Chatterjea, 1998). Like elsewhere in the tropics, storm events are limited spatially to less than $10 \mathrm{~km}^{2}$ (Gupta and Ahmad, 1999), but come with considerable gradients in intensity and amount (Jackson, 1989). Rainfall from a single cumulonimbus cloud can vary from about 2 $\mathrm{km}^{2}$ to $60 \mathrm{~km}^{2}$ spatially (Dale, 1959; 1960).

With more than $50 \%$ of the total sediment load transported by rivers taking place in just a few days annually from major storm events (Douglas, 1993), the need to understand the effects of sedimentation from storm events becomes all the more crucial. With a population of over 5 million (Statistics Singapore, 2010), Singapore has one of the highest population densities (exceeding 7000 per $\mathrm{km}^{2}$ ) in the world. The rapid pace of urbanizations has seen changes including the modification of natural drainage routes into planned, concretized drainage network. Diversions and the straightening of channels are widespread engineering practices in Singapore.

This research came about from a development strategy of Singapore, the Marina Barrage. Envisioned by then Prime Minister, Mr. Lee Kuan Yew more than 2 decades ago, the Barrage was commissioned on $1^{\text {st }}$ November 2008 (PUB, 2008). Becoming the $15^{\text {th }}$ reservoir in Singapore, the reservoir behind the barrage has increased the catchment area of Singapore from half to two-thirds. The entire catchment area $\left(116.37 \mathrm{~km}^{2}\right)$ of Marina Barrage will span largely across the central and southern part of main island of Singapore (Figure 1). It can be sub-divided into five smaller catchments .Kallang subcatchment, the largest, covering an area of $33.02 \mathrm{~km}^{2}$, Geylang subcatchment $\left(9.83 \mathrm{~km}^{2}\right)$ and Alexandra subcatchment $\left(14.71 \mathrm{~km}^{2}\right)$ are the main areas under study.

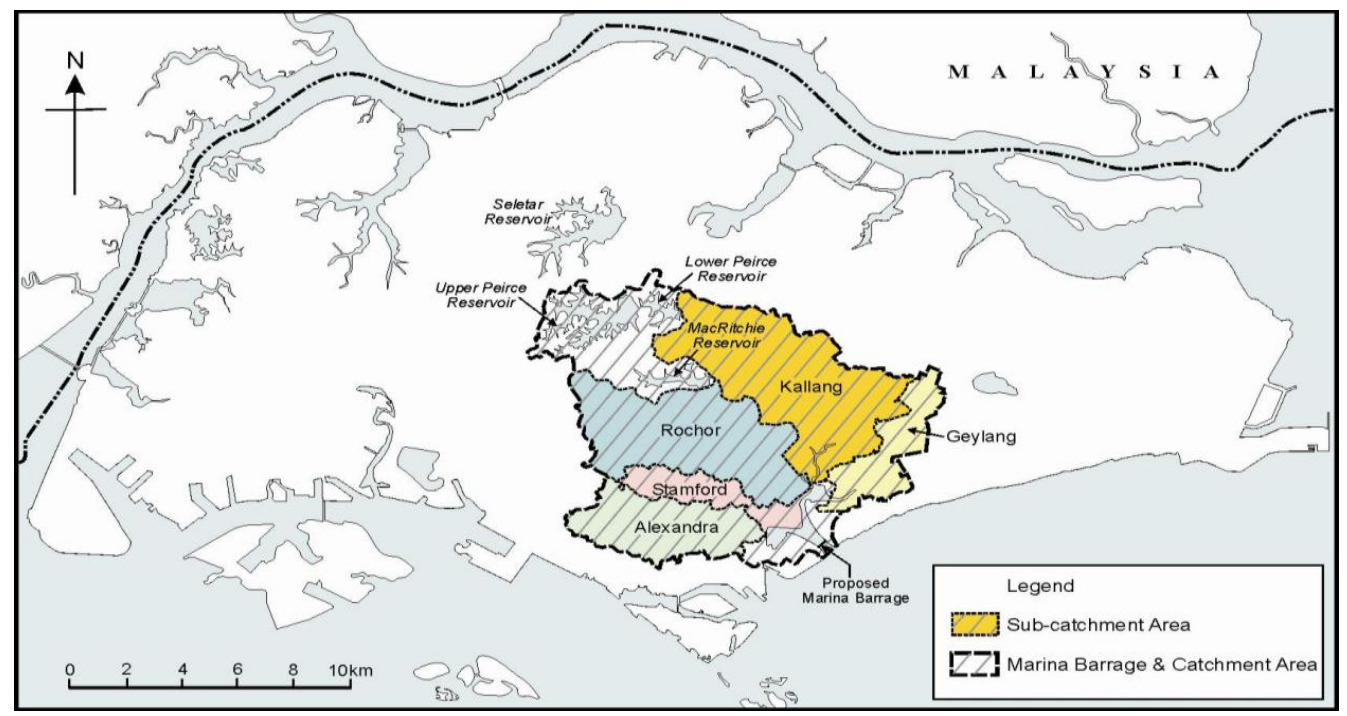

Figure 1. Map of Marina Barrage catchment and its subcatchments (Source: Author's own) 
Sedimentations, contaminations and eutrophication are three pronounced concerns as they can jeopardize the water quality as well as the aesthetics of the reservoir. Water quality and sedimentations are of paramount concern to any water resource managers. Sediments trapped behind dams will decrease reservoirs' capacity and eventually lead to decommissioning of dams. This can have significant economic repercussions for the island-state. As such, this paper seeks to address part of the concerns by looking at the dynamics of suspended sediment loads through storm hydrological characteristics.

\section{METHODOLOGY}

The four gauging stations are Bishan and Braddell (located at the upstream and downstream of Kallang subcatchment respectively), Alexandra and Geylang. Autosamplers, and multiparameter probes were used to collect storm water and other water parameters in the gauging stations. Turbidity probe, YSI 6920 v2, was added to Alexandra and Geylang stations subsequently as the equipment became availability. $Q$ was calculated based on Manning's open channel equation after manual trial samplings of flow velocity were found to be compatible to the equation.

Event-based sampling was chosen because most of the SS are transported during storm events. 24 samples of storm water with an interval of 2.5 minutes were collected throughout each storm event. An hour of sampling at the given intervals was collected because storm events in the area typical cease within an hour. The autosamplers were triggered by a distinct change in height of the water level in the channels (i.e. at least $0.4 \mathrm{~m}$ ) as well as a significant amount of rainfall intensity (i.e. at least $12 \mathrm{~mm} / \mathrm{hr}$ ). Both requirements are determined after a month of field observations and trial data collection. They also serve to prevent the collection of non-event samples. A HOBO tipping buckets rain gauge was installed next to the sampler to collect rain data.
The triggering of the autosamplers was relayed via short message services (SMS) through a modem installed to the autosamplers. This allowed us to collect the samples at the earliest possible moment. Back in the laboratory, SS are filtered using preweighed Whatman glass filter paper of $47 \mathrm{~mm}$ diameter, and pore size of $0.7 \mu \mathrm{m}$. They are then oven-dried and weighed.

A total of 34 storm events (from January 2007 March 2008) were included for this analysis. Two events from Braddell have been excluded as a result of the inability to derive an accurate extrapolation and the rainfall data were lost during download from autosamplers to the Rapid Transfer Device (RTD) respectively. Total loads from a storm event should ideally include the entire rising and falling limb of the hydrograph, but samples collected from the autosamplers did not necessarily encapsulate the entire storm hydrograph period. As such, extrapolation of SS concentration was used to derive the entire storm hydrograph.

Extrapolation was facilitated by the good SSturbidity rating relationship for Alexandra and Geylang. Storm events (in Alexandra and Geylang) missing the first few minutes of the rising limb, as well as, the end portion of the receding limb, were extrapolated using turbidity data. Good turbidity and SS concentration correlation facilitated this (Figure 2). For events sampled in Bishan, improvements made to the SS- $Q$ rating curves (Figure 3) through temporal segregation of data were used to extrapolate the few missing data ${ }^{1}$. Temporal segregation includes seasonal variability and stage variability. However, SS concentration for the Braddell events could not be extrapolated due to the lack of turbidity data and the poor rating relationship of SS- $Q$. Nevertheless, all but two of the storm events are incorporated for the regression analysis as they are only missing a small segment of the rising limb (less than 3 minutes) and a segment of the low SS concentration receding limb (less than 10 minutes).

\footnotetext{
${ }^{1}$ Details of extrapolation and rating curves will be discussed in a separate paper, forthcoming.
} 

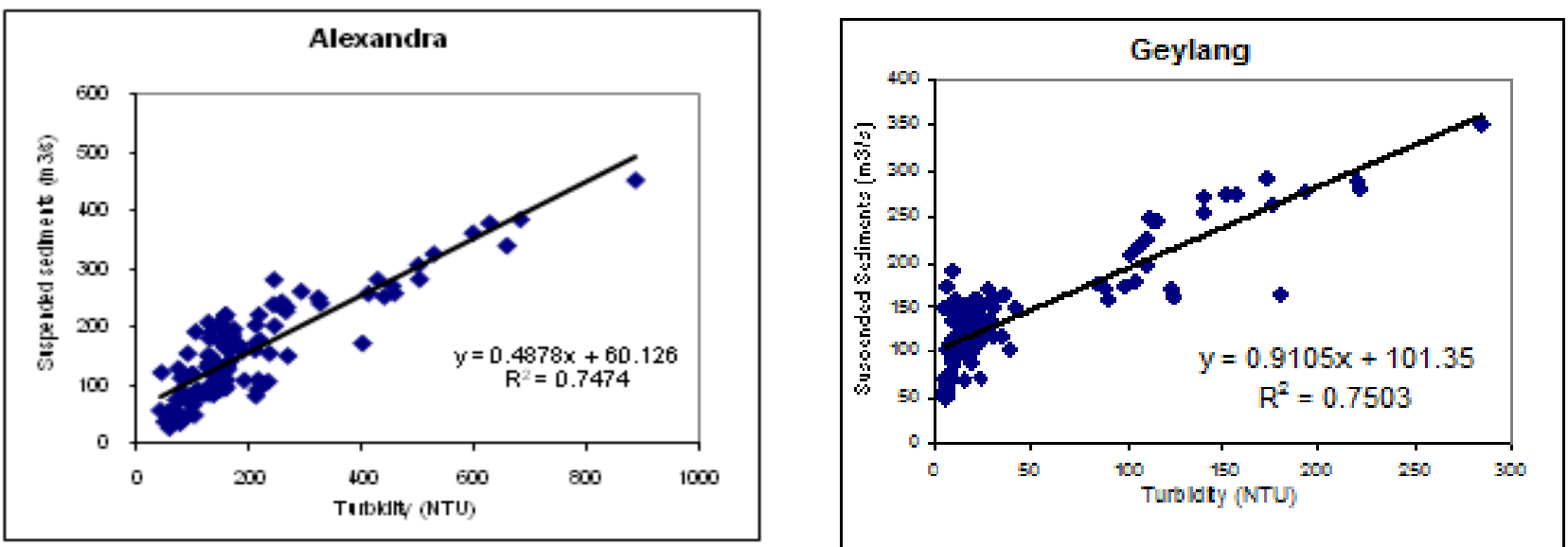

\section{- Storm samples}

Figure 2. Rating relationship of SS concentration and turbidity of Alexandra and Geylang respectively
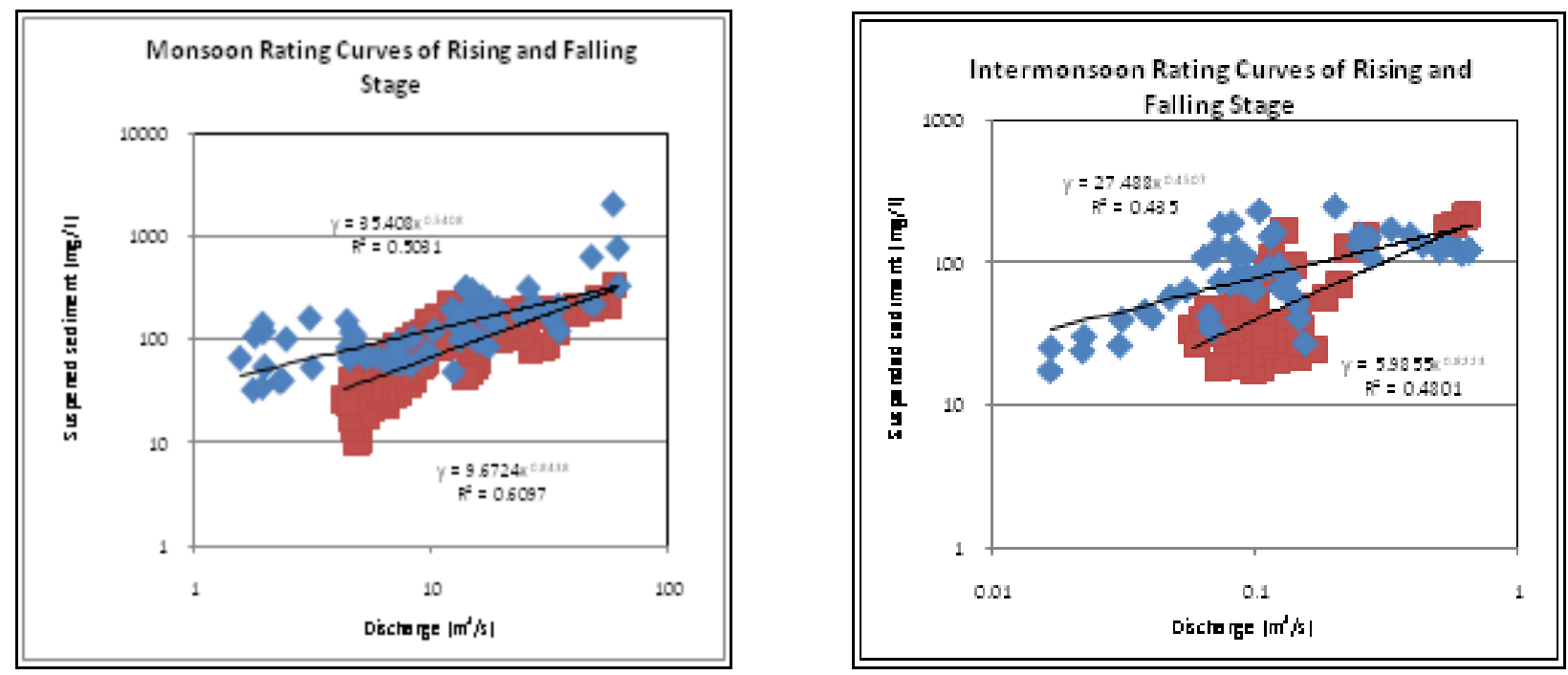

\section{- Rising Stage $\square$ falling stage}

Figure 3. Improved Sediment Rating Curves of Bishan Station divided into monsoon/intermonsoon and rising/falling stage of storm events 


\section{REGRESSION ANALYSIS}

$Q$-based data, rainfall data and pre-event hydrological characteristics adapted from Hémain (1985) and Wolting \& Bouvier (2002) are the primary hydrological characteristics collected. The hydrological characteristics of individual storm events are namely, (i) maximum $Q$ (Q_max): peak discharge during an event; (ii) total $Q$ (Q_tot): total discharge under the storm hydrograph; (iii) rainfall duration (Rf_dur) and; (iv) rainfall intensity (Rf_int). The rainfall data are derived from the rainfall data collected from the respective rain gauges during storm events.

Durations of varying rainfall intensities are also tabulated. They are namely, (i) duration of rainfall exceeding $12 \mathrm{~mm} / \mathrm{h}$ (Di_12) and (ii) duration of rainfall exceeding $60 \mathrm{~mm} / \mathrm{h}$ (Di_60). In addition, three simple pre-event characteristics are included to understand dominating effects of antecedent conditions, if any. These conditions include, length of antecedent dry days from last rain event (AD_days); its duration (ARf_dur) and; maximum intensity (ARf_int).

Some assumptions are made here: (i) there is a lack of transient anthropogenic events (i.e. construction activities) just before and during the individual sampling events and; (ii) no major changes have been made to the land cover in the catchment area. These will help eradicate concerns of extraordinary SS loads and time-transportation from sources respectively. These assumptions are made because no excessive loads were found under baseflow conditions prior to the individual storms and no major land cover changes were witnessed in the catchment.

Previous works on understanding effects of differing hydrological characteristics' have commonly used multiple regression models. (e.g. Kleiss, 1996; Willis et al, 1998; Hodson and Ferguson, 1999). Figure 4 shows the XY plots of relationships between SS loads and the respective variables.
The problem of heteroscedasticity is noted for the best-fit regression lines in some of the plots. None of the pre-event hydrological characteristics was to have any significant correlation with the loads of respective events and hence left out of the regression analysis. In addition, the duration of the rainfall was also discarded due to the absence of significant correlation. Curvilinear plots were noted for RF_int, Di_12 and Di_60 and transformations were done for the data to conform to the requirements of a general linear model. It is useful to subsequently determine the correlation of the independent variables to avoid autocorrelation if multiple linear regression models are adopted.Pearson Correlation was used to provide some basic understanding on the correlation between the independent variables before a regression model was chosen.

From Table 1, it can be seen that there exists some statistical significant, strong relationships between some of the independent variables. For example, the independent variables, Di_12 and Rf_dur have a strong positive correlation of 0.769 at a significant level $(<0.001)$. This does not, however, means that one of these variables should be removed from the data pool as it remains unclear thus far, which is the dominating factor. Removing it will potentially reduce the accuracy of the model predicted.

To further avoid the auto-correlation when using multiple linear regressions, stepwise linear regression model is used instead of the multiple entry method. A backward stepwise method is employed using SPSS software. This is a useful method in doing exploratory work to find a preliminary model to fit the data collected (Field, 2005). This is justified because no previous work has been done on the hydrological characteristics and SS loads models in the Marina Barrage Catchment. The computer begins with a model that includes all predictors. It will then test and removed any of these predicators that do not have a substantial effect on the fitting of the models the observed data when removed (ibid). 

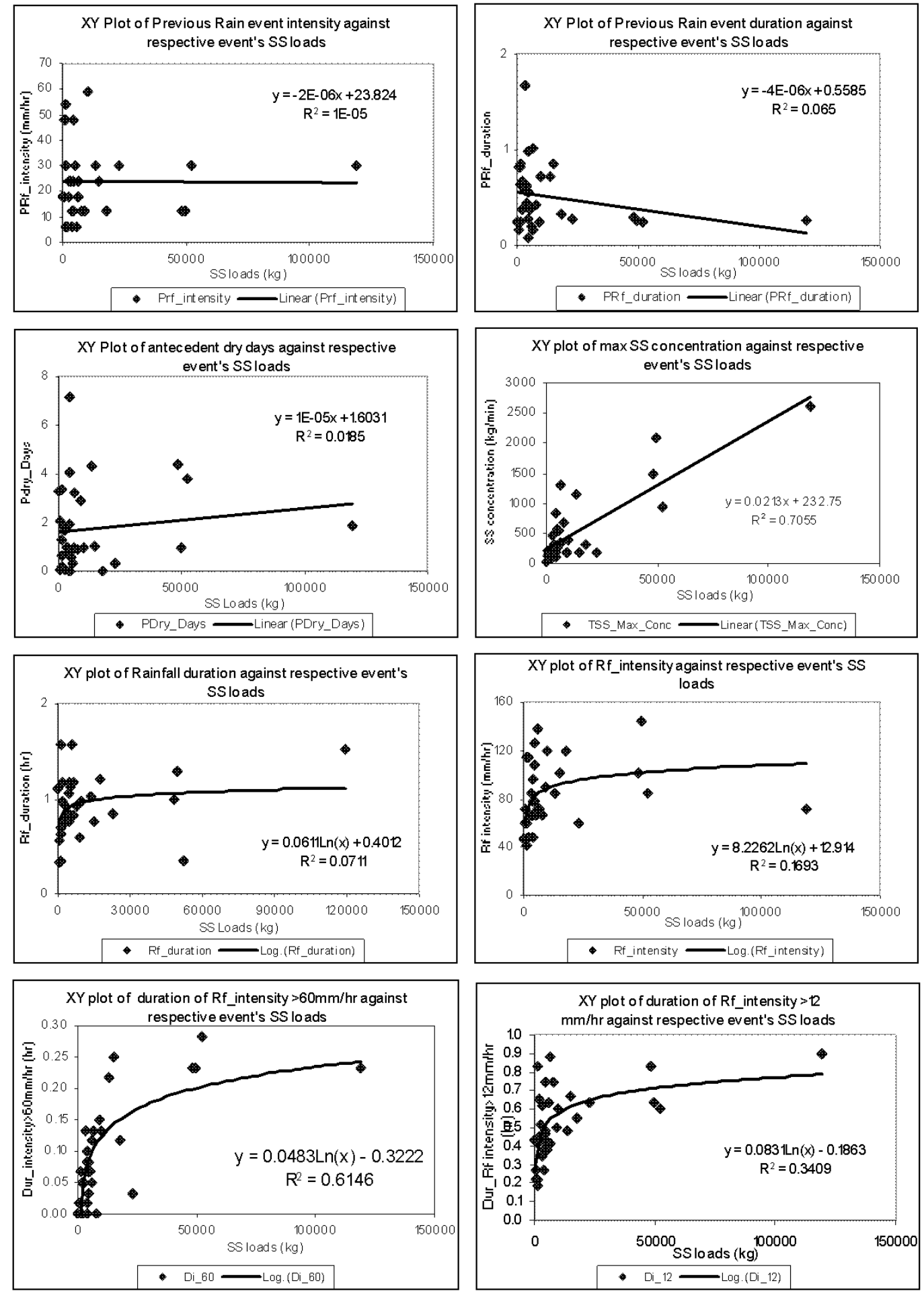

Figure 4. XY plots showing relationships between SS loads and the respective variables 
Table 1. Pearson correlation of the variables (hydrological characteristics and total loads)

\begin{tabular}{|c|c|c|c|c|c|c|c|c|c|c|c|c|}
\hline & & $\begin{array}{l}\text { TSS_ } \\
\text { Max_ } \\
\text { Conc }\end{array}$ & Q_max & Q_tot & $\begin{array}{l}\mathrm{Q}_{-} \\
\text {Mean }\end{array}$ & $\begin{array}{l}\mathrm{Rf}_{-} \\
\text {duration }\end{array}$ & $\begin{array}{l}\mathrm{Rf}_{-} \\
\text {intensity }\end{array}$ & Di_12 & Di_60 & $\begin{array}{l}\mathrm{PDr}_{-} \\
\text {Days }\end{array}$ & $\begin{array}{l}\mathrm{PRf}_{-} \\
\text {duration }\end{array}$ & $\begin{array}{l}\text { Prf_- } \\
\text { intensity }\end{array}$ \\
\hline Pearson & TSS_Loads & $.697^{* *}$ & $.622^{* *}$ & $.875^{* *}$ & $.853^{* *}$ & 0.278 & 0.162 & $.307^{*}$ & 0.201 & 0.136 & -0.255 & -0.004 \\
\hline \multirow[t]{14}{*}{ Correlaton } & TSS_Max_Conc & & $.879^{* *}$ & $.651^{* *}$ & $.556^{* *}$ & $.401^{* *}$ & 0.207 & $.557^{* *}$ & 0.123 & $.374^{*}$ & 0.006 & 0.021 \\
\hline & $\begin{array}{l}\text { TSS_Mean_Con } \\
\text { c }\end{array}$ & & $.861^{* *}$ & $.542^{* * *}$ & $.468^{* * *}$ & $.341^{*}$ & 0.276 & $.600^{* * *}$ & $.455^{* *}$ & $.445^{* *}$ & -0.088 & 0 \\
\hline & Q_max & & & $.640^{* *}$ & $.650^{* *}$ & 0.262 & 0.17 & $.529^{* * *}$ & $.324^{*}$ & $.385^{*}$ & $\begin{array}{l}-0.000 \\
-0.016\end{array}$ & -0.04 \\
\hline & Q_tot & & & & $.856^{* *}$ & 0.14 & 0.171 & 0.259 & 0.282 & 0.191 & -0.128 & -0.031 \\
\hline & Q_Mean & & & & & 0.121 & 0.093 & $.289^{*}$ & 0.205 & 0.088 & -0.177 & 0.009 \\
\hline & Rf_duration & & & & & & & & & - & & \\
\hline & & & & & & & 0.151 & $.769^{* *}$ & $.305^{*}$ & 0.017 & -0.019 & -0.127 \\
\hline & Rf_intensity & & & & & & & 0.227 & $.658^{* * *}$ & 0.003 & -0.103 & 0.075 \\
\hline & Di_12 & & & & & & & & $.576^{* * *}$ & 0.171 & 0.039 & -0.025 \\
\hline & Di_30 & & & & & & & & $.748^{* *}$ & 0.085 & 0.126 & 0.099 \\
\hline & Di_60 & & & & & & & & & 0.05 & -0.014 & -0.037 \\
\hline & PDry_Days & & & & & & & & & & 0.037 & 0.269 \\
\hline & PRf_duration & & & & & & & & & & & 0.138 \\
\hline & Prf_intensity & & & & & & & & & & & \\
\hline
\end{tabular}

**. Correlation is significant at the 0.01 level (1-tailed)

*. Correlation is significant at the 0.05 level (1-tailed) 
The following tables show the output of the stepwise regression models. Table 2 shows the model summary; Table $\mathbf{3}$ shows the analysis of variance (ANOVA) and; Table 4 shows the coefficients in the models.

From Table 2, Model 1 and 2 have R Square values of 0.706 and 0.762 respectively. Essentially, peak SS concentration accounts for 0.706 of the variability in this outcome alone. However, when duration of rainfall intensity exceeding $60 \mathrm{~mm} / \mathrm{hr}$ is included into the model (i.e. model 2), both of these variables can account for 0.762, an improvement of 0.056 (7.93\%). The close values of the adjusted R Square to the original R Square gives an idea that both models generalizes well, with less than $2 \%$ variance in the outcome if the population rather than a sample of it is used.

Table 3 contains the ANOVA that tests whether the model is significantly better at predicting the outcome than merely using the mean as a guess. The large values for the sum of squares represent a huge improvement in prediction resulting from fitting a regression line to the data rather than using the mean. The proportion of improvement, $R^{2}$ (model sum of squares $\left[\mathrm{SS}_{\mathrm{m}}\right] /$ total sum of squares
$\left.\left[\mathrm{SS}_{\mathrm{t}}\right] \times 100\right)$ is $70.6 \%$ and $76.2 \%$ for Model 1 and 2 respectively. The $F$-ratio is a measure of the improvement of the prediction of the outcome compared to the level of inaccuracy of the model (mean square of the model $\left[\mathrm{MS}_{\mathrm{m}}\right] /$ residual mean square $\left[\mathrm{MS}_{\mathrm{r}}\right]$. Both models yield high $F$-ratio of 76.7 and 49.7 respectively and they are very unlikely to have happened by chance $(p<.001)$. Given these, both models seem to be able to improve the ability to predict the outcome variable and both regression models are significant.

The Coefficient Table gives a summary of the coefficient in the models and the $t$-tests. The high $t$ value for Model 2 rejects the null hypothesis that the coefficient is zero at high significant levels ( $\mathrm{p}<$ 0.001 ), thus it can be said that the predictor variables contribute significantly to Model 2.

The $F$-ratio and the $t$-tests are significant for Model 2 and the slightly better $R^{2}$ value of 0.762 provides a conclusion that Model 2 is a better regression model. Hence, we derive the following regression model,

Loads $=25.968($ TSS_max_conc $)+832.958$

(Di_60) - 5295.269

Table 2. Model Summary of Regression Models

\begin{tabular}{ccccc}
\hline Model & Predictors & R & R Square & $\begin{array}{c}\text { Adjusted R } \\
\text { Square }\end{array}$ \\
\hline 1 & i) TSS_Max_Conc & $.840(\mathrm{a})$ & .706 & .696 \\
2 & $\begin{array}{r}\text { i) TSS_Max_Conc } \\
\text { ii) Di_60 }\end{array}$ & $.873(\mathrm{~b})$ & .762 & .747 \\
\hline
\end{tabular}

Table 3. ANOVA of Regression Models

\begin{tabular}{|c|c|c|c|c|c|c|}
\hline Model & & Sum of Squares & Df & Mean Square & $\mathrm{F}$ & Sig. \\
\hline \multirow[t]{3}{*}{1} & Regression & $1.259 \mathrm{E} 10$ & 1 & $1.259 \mathrm{E} 10$ & 76.664 & $.000(a)$ \\
\hline & Residual & $5.257 \mathrm{E} 9$ & 32 & $1.643 \mathrm{E} 8$ & & \\
\hline & Total & $1.785 \mathrm{E} 10$ & 33 & & & \\
\hline \multirow[t]{3}{*}{2} & Regression & $1.361 \mathrm{E} 10$ & 2 & $6.805 \mathrm{E} 9$ & 49.735 & $.000(\mathrm{~b})$ \\
\hline & Residual & $4.242 \mathrm{E} 9$ & 31 & $1.368 \mathrm{E} 8$ & & \\
\hline & Total & $1.785 \mathrm{E} 10$ & 33 & & & \\
\hline
\end{tabular}


Table 4. Coefficients of Regression Models

\begin{tabular}{|c|c|c|c|c|c|c|}
\hline \multirow{2}{*}{ Model } & & \multicolumn{2}{|c|}{$\begin{array}{c}\text { Unstandardized } \\
\text { Coefficients }\end{array}$} & \multirow{2}{*}{$\begin{array}{c}\text { Standardized } \\
\text { Coefficients } \\
\text { Beta }\end{array}$} & \multirow{2}{*}{$\mathrm{T}$} & \multirow{2}{*}{ Sig. } \\
\hline & & B & Std. Error & & & \\
\hline \multirow[t]{2}{*}{1} & (Constant) & -3893.537 & 2918.067 & & -1.334 & .192 \\
\hline & $\begin{array}{c}\text { TSS_max_co } \\
n c\end{array}$ & 33.063 & 3.776 & .840 & 8.756 & .000 \\
\hline \multirow[t]{3}{*}{2} & (Constant) & -5295.269 & 2712.322 & & -1.952 & .000 \\
\hline & $\begin{array}{c}\mathrm{TSS} \_m a x \_c o \\
n c\end{array}$ & 25.968 & 4.320 & .660 & 6.012 & .000 \\
\hline & Di_60 & 832.958 & 305.756 & .299 & 2.724 & .010 \\
\hline
\end{tabular}

a. Dependent Variable: TSS_Loads

\section{DISCUSSION AND CONCLUSION}

From the model, it can be concluded thus far, that two hydrological characteristics, i) peak SS concentration and, ii) duration of rainfall intensity of more than $60 \mathrm{~mm} / \mathrm{hr}$, account for most of the event's load variability. Values of TSS_max_conc and Di_60 are applied to the model to understand the extent of under/over estimation. It is noted that the low coefficient of TSS_max_conc and the high negative constant value, resulted in very poor prediction of events when SS loads are less than $170 \mathrm{~kg} / \mathrm{min}$.

It must be clarified, thus far, that this method of modeling is primarily used to derive an understanding to the key hydrological characteristics that accounts for the suspended sediment loads in urban tropical channels. It will require further fieldwork and research to harness sufficient storm events and data to derive a more accurate model for prediction purposes. Nonetheless, this regression analysis has provided us with an insight to the hydrological functions that dominate urban, tropical rivers during storm events. More importantly, it has provided the two key hydrological characteristics that can help estimate sediment loads transported during storm events in tropical urban channels.

An extended duration of high intensity rain will result in greater amount of SS loads transported. The highly impervious urban surfaces bring about rapid runoff channeling into the drainage network. During storm events, this provides a high level of energy that carries surface sediments rapidly into the efficient drainage network in Singapore during an event. Concretized and straightened channels also facilitate transportation of flow and sediments. In addition, deposited sediments in the channels can be rapidly (re)suspended and carried downstream. Figure 5 gives a summary of the flow process. In sum, in a highly impervious surface environ, the greater the intensity of the rain, the more energy derived from discharge and hence, more loads transported.

The typical steep rising and falling limbs of the urban storm hydrograph implies that the bulk of the energy available to transport sediments is at/near the peak of the hydrograph. The sharp rising and falling limbs of urban storm hydrograph provides a rapid rate of change in $Q$. As more water is rapidly made available in the initial phase of an event, a great amount of sediment can be transported into the drainage channels. Therefore, it is justifiable that peak SS concentration is a good indicator to the amount of loads transported.

It can therefore be argued that the highly urbanized environment, coupled with the short but intense tropical storm events play an important role in the hydrological characteristics that help determine the SS loads. In retrospect, the regression model derived has the potential to achieve much more in the future for the management of the Marina Barrage catchment. This however, will require more research and data to be collected in the various subcatchments in the near future. It will allow for a better and more representative data set available, and hence more regression models (for each subcatchment) will be available to help predict the annual loads depositing into the Marina Barrage Reservoir. This has significant implications especially in the need to understand the carrying capacity and life span of the reservoir, and subsequently derive mitigation methods against high rates of sedimentation. 


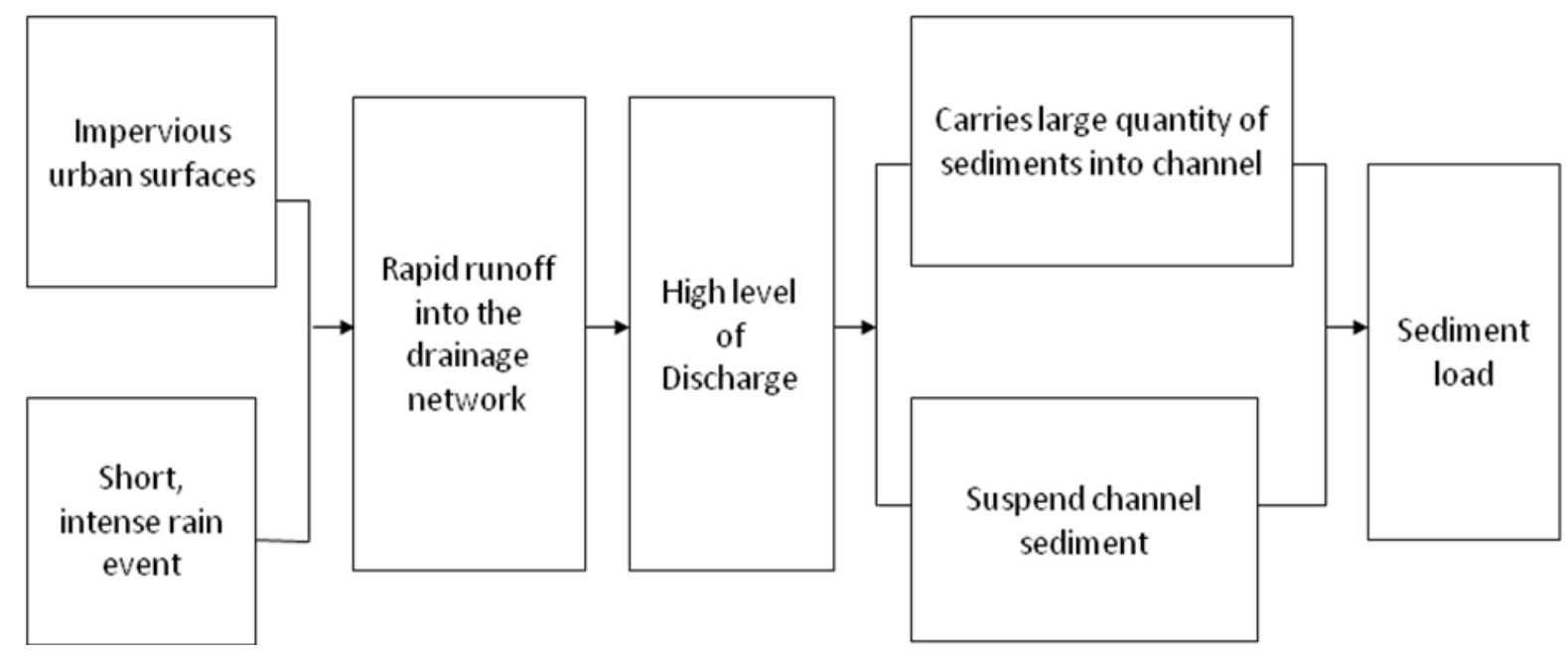

Figure 5. Effects of urbanization and tropical climatic conditions on sediment load

\section{ACKNOWLEDGMENTS \& NOTES}

The author extends his thanks to Professor David Higgitt, National University of Singapore (NUS) for his valuable input and comments, as well as to Tropical Marine Science Institute, (NUS) for the graduate research scholarship and funding for this project.

This paper was presented in the $6^{\text {th }}$ Mathematics and Physical Science Congress (MPSGC), University of Malaya, Malaysia. Special Thanks to Chairman of $6^{\text {th }}$ MPSGC, Mr. Ngoi Siew Kien for facilitating this paper submission.

\section{REFERENCES}

1. Bonell, M. \& Bruijnzeel, L.A. (2005), Forests,water and people in the humid tropics: Past, present and future hydrological research for integrated land and water management, Cambridge University Press.

2. Chatterjea, K. (1998), The impact of tropical rainstorms on sediment and runoff generation from bare and grass-covered surfaces: A plot study from Singapore, Land degradation and Development, Volume 9(2), pp. 143-157.

3. Chui, P.C. (1997), Characteristics of stormwater quality from two urban watersheds in Singapore, Environmental
Monitoring and Assessment, Volume 44, pp. 17381.

4. Dale, W.L. (1959), The rainfall of Malaya (Part 1), Journal of Tropical Geography, Volume 13, 23-

5. Dale, W.L. (1960), The rainfall of Malaya (Part 2), Journal of Tropical Geography, Volume 14, 1128.

6. Douglas, I. (1993), The Tropics: Environments and human impacts understood and reinterpreted, Singapore Journal of Tropical Geography, Volume 14(2), pp.103-122.

7. Field, A.P. (2005), Discovering statistics using SPSS, London: Sage.

8. Goonetilleke, Ashantha \& Thomas, Evan C. (2003), Urban water quality and the triple bottom line - Can we reconcile the irreconcilables? In Douglas, B. and Furnass, B. \& Goldie, J.(eds.), Proceedings in search of sustainability.

9. Gupta, A. \& Ahmad, R. (1999), Geomorphology and the urban tropics: Building an interface between research and usage, Geomorphology, Volume 31, pp. 133-149.

10. Hodson, A.J. \& Ferguson, R.I. (1999), Fluvial suspended sediment transport from cold and warm-based glaciers in Svalbard, Earth Surface Processes and Landforms, Volume 24(11), pp. 957-974. 
11. Jackson, I.J., (1989), Climate, water and agriculture in the tropics, $2^{\text {nd }}$ ed., Burnt Mill, Harlow, Essex, England: Longman Scientific \& Technical; New York: Co-published in the U.S. with Wiley.

12. Khanchoul, K. \& Jansson, B.M. (2008), Sediment rating curves developed on stage and seasonal means in discharge classes for the Mellah Wadi, Algeria, Swedish Society for Anthropology and Geography, Geografiska. Annaler: Series A., Volume 90(3):pp. 227236.

13. Kleiss, B.A. (1996), Sediment retention in a bottomland hardwood wetland in eastern Arkansas, Wetlands, Volume 16(3), pp. 321333.

14. Lim, H.S. (2000), Variations in the water quality of a tropical urban catchment: The Singapore River, National University of Singapore, Department of Geography, Unpublished Honours Thesis.

15. Lim, H.S. (2003), Variations in the water quality of a small urban tropical catchment: implications for load estimation and water quality monitoring, Hydrobiologia, Volume 494(1-3), pp. 57-63.

16. Public Utilities Board, Singapore (2005), PreBarrage water quality report, PUB (unpublished research report).

17. Watts, I.E.M. (1955), Rainfall in Singapore island, The Malayan Journal of Tropical Geography, Volume 7, pp. 80-131.

18. Willis, I.C., Richards, K.S. \& Sharp, M.J. (1998), Links between proglacial stream suspended sediment dynamics, glacier hydrology and glacier motion at Midtdalsbreen, Norway, Hydrological Processes, Volume 19(4), pp. 629-648.

Online access:

19. PUB (2008), Singapore's first reservoir in the city realized, press release http://www.pub.gov.sg/mpublications/Pages/Pr essReleases.aspx? ItemId $=188 \& y=2008$ (accessed 01 December 2010)

20. Statistics Singapore, Singapore (2010), Singapore population estimates, http://www.singstat.gov.sg/stats/themes/people /demo.html (accessed 01 December 2010). 